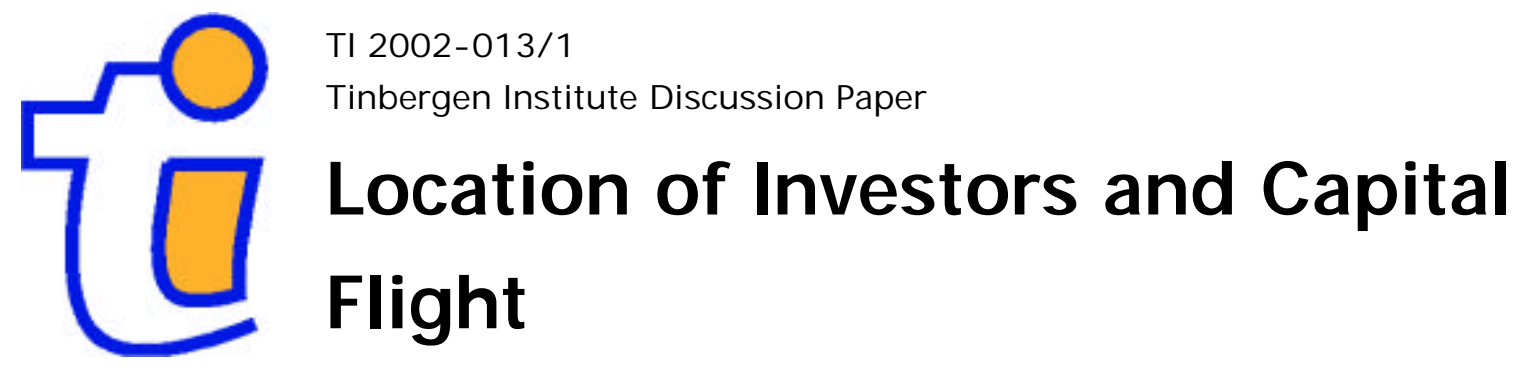

Dennis P.J. Botman ${ }^{1}$

Cees G.H. Diks²

1 The World Bank, Washington DC,

${ }^{2}$ CeNDEF, Faculty of Economics and Econometrics, University of Amsterdam, and Tinbergen Institute 
Tinbergen Institute

The Tinbergen Institute is the institute for economic research of the Erasmus Universiteit Rotterdam, Universiteit van Amsterdam and

Vrije Universiteit Amsterdam.

Tinbergen I nstitute Amsterdam

Keizersgracht 482

1017 EG Amsterdam

The Netherlands

Tel.: +31.(0)20.5513500

Fax: $\quad+31 .(0) 20.5513555$

Tinbergen Institute Rotterdam

Burg. Oudlaan 50

3062 PA Rotterdam

The Netherlands

Tel.: $\quad+31 .(0) 10.4088900$

Fax: $\quad+31 .(0) 10.4089031$

Most TI discussion papers can be downloaded at

http://www.tinbergen.nl 


\title{
Location of Investors and Capital Flight*
}

\author{
Dennis P.J. Botman ${ }^{a}$, Cees G.H. Diks ${ }^{b, \dagger}$ \\ ${ }^{a}$ The World Bank, Washington DC \\ ${ }^{\mathrm{b}}$ CeNDEF, Faculty of Economics and Econometrics, University of Amsterdam, and \\ Tinbergen Institute, Roetersstraat 11, 1018 WB, Amsterdam, The Netherlands
}

January 22, 2002

\begin{abstract}
This paper utilizes a very simple model to study the timing and determinants of speculation against a fixed exchange rate regime when investors are heterogeneous because of locational differences. Location matters because resident players may incur smaller costs when taking a short-position, are less exposed to exchange rate risk, possess better information quality, have more knowledge about each others information sets, due to asymmetries in tax treatment, or because of the presence of government guarantees. Our model clarifies the respective roles played by local and international investors during episodes of capital flight as well as the resulting room of maneuver for policymakers in emerging markets.
\end{abstract}

Keywords: Locational heterogeneity; Private information; Exchange rate volatility; Illiquidity; Capital flight

JEL classification: F32; F34; D84

\section{Introduction}

In the international finance literature there is much emphasis on the distinctive nature of resident and foreign investors. For example, one of its stylized facts is the presence of the home bias: portfolios are not diversified internationally as much as one would expect given its potential benefits. Market participants invest relatively more in local assets. Also, at least since the Mexican Peso crisis, attention has been given to the possible implications of the presence of both foreign and local investors for the timing of an episode of capital flight. In particular, some researchers have argued that it are often local players that

${ }^{*}$ Diks' research is supported by the Netherlands Organization for Scientific Research (NWO) under a MaG-Pionier grant.

${ }^{\dagger}$ Corresponding author. Tel.: +31-20-5255329; fax: +31-20-5254349. E-mail address: diks@fee.uva.nl (C.G.H. Diks). 
transfer their wealth abroad after the first signs of trouble. Location matters because it not only affects the moment of a financial crisis, but also its ultimate determinants depending on which players take the lead during an episode of capital flight. If it are indeed the local investors that play a leading role in starting a process of capital flight, possibly resulting in a financial crisis with large output losses as a consequence, then this could have important implications for the formulation of policies that are intended to deal with volatility in the global capital market, for example with respect to the desirability of capital flows.

The International Monetary Fund review of the Mexican experience emphasized the role of domestic capital flight, finding that "the available data show that the pressure on Mexico's foreign exchange reserves during 1994, and in particular just prior to the devaluation, came not from the flight of foreign investors or from speculative positiontaking by these investors, but from Mexican residents" (IMF, 1995). Frankel and Schmukler $(1996,1998)$ also report instances where it were indeed local investors that left their markets before international investors did at times of crises. Such an observation is consistent with local investors being better informed. Like explanations for the existence of the home bias, the empirical literature that tries to separate trading activities of local and foreign players on financial markets sees information differences, in the sense of the former party having access to better information than the latter, as the prime cause for observed differences in behavior.

Choe, Kho, and Stulz (2000) and Kim and Wei (1999) analyze data of South Korea to study trading patterns by resident and international investors respectively. These papers find evidence for a short-lived informational advantage for individual stocks of domestic investors over foreign investors, respectively that international investors engage in positive feedback trading. Kaufmann, Mehrez, and Schmukler (1999) investigate whether enterprise managers have an information advantage about the countries they work on. Indeed, when looking at some recent crises countries, they find support for the hypothesis that local managers have private information. Also, they find that the local business community anticipated the crisis in South Korea, Thailand, and Russia, but not in Indonesia and Malaysia. Choe, Kho, and Stulz (1999) find no support for the claim that it were the foreign equity investors that played a destabilizing role during East-Asia's emerging stock market crises.

This paper utilizes a very simple model to study the determinants of the moment of speculation as well as possible dependence of this moment on heterogeneity of investors stemming from locational differences. Market participants are assumed to be heterogeneous for two reasons. First of all, they possess private information about the degree of overvaluation of the currency. Second of all, agents can be either residents or foreign investors. We offer a number of explanations for the empirical observation that resident investors often play a leading role during such episodes of capital flight. Our model for the determinants of the moment of capital flight and the impact of different causes for heterogeneity of market participants, has both features of illiquidity and exchange rate 
uncertainty. ${ }^{1}$

The intuition for the model is as follows. Investors lend to a bank in an emerging market. The bank in turn invests the loan in projects that can have either a short-term or long-term character. This feature captures the idea that, during recent crises, capital flows went mostly to the private sector and were increasingly intermediated by the banking sector in emerging markets. Investments are illiquid both because the long-term investments can only be terminated with some loss and because short-term external debt exceeds the amount of official reserves.

In the presence of a fixed exchange rate regime, the asset-liability and maturity mismatch facing the borrowing bank provides a subtle role for overvaluation of the exchange rate. In case the currency is perceived to be overvalued by a certain degree, it becomes optimal to refuse to roll-over the loan and to speculate against the fixed parity instead. Then, the borrowing bank may have difficulty servicing its debt obligations because of both a devaluation of the currency and because long-term assets are terminated with a loss. The extent of misalignment of the fixed exchange rate provides investors with financial risks on the one hand, and interesting profit opportunities in case they become speculators on the other hand. Thus, in our model, overvaluation of the currency is crucial during episodes of capital flight and this is confirmed by the empirical analyzes in Collier, Hoeffler, and Pattillo (1999). ${ }^{2}$ As a consequence, the moment of capital flight is expressed in our model by a threshold value of the equilibrium exchange rate compared to the fixed exchange rate.

Location of the investor matters for the following five reasons in our framework. First of all, resident investors may incur lower costs in case they want to speculate against the fixed exchange parity as foreign parties need to borrow the domestic currency. The second reason why location is important refers to the idea that, although loans are made in the foreign currency, international investors are still exposed to exchange rate risk. After all, in case reserves are exhausted and the exchange rate collapses, servicing debt repayment on foreign currency obligations becomes more expensive for the borrowing bank in the emerging market. The basic model with these two ingredients is developed in section 2 under the condition that the participation of both parties is required for the speculation to be effective. In section 3 we analyze the model under the condition that the participation of either party satisfies to attack the fixed exchange rate regime successfully.

A third reason why location could matter is that the quality of the information possessed by resident respectively foreign players may be different. In section 4 we discuss the case where domestic parties receive better information than their foreign counterparts about the fundamentals of the economy. A fourth difference between domestic and foreign investors could be that the former are often exposed to higher taxation on wealth that has not been moved abroad in case of a crisis. This affects both the timing and the determinants of a moment of capital flight and is the subject of section 5. Then in Section 6 we show that government guarantees create a fifth difference between local and international

\footnotetext{
${ }^{1}$ For the former see, for example, Diamond and Dybvig (1983) and Chari and Jagannathan (1988).

${ }^{2}$ See Botman and Jager (2002) for a model in which the extent of overvaluation of the currency before a balance of payments crisis is determined by coordination problems among speculators.
} 
investors in case they work discriminatory in favor of resident investors. Section 7 concludes and discusses the policy implications of our model which are related to transparency, the effectiveness of capital controls, the influence of portfolio diversification, and asset-liability management.

\section{Location and Capital Flight}

\subsection{Definitions and Assumptions}

As we want to study the issue of location in a model as simple as possible we do not include two different types of players. Instead we assume that a fraction of each players' investment is denominated in the local currency and the remainder is denominated in the foreign currency. The former fraction is denoted by $\phi$ and the latter by $(1-\phi)$. For example, this situation could resemble the diversification of individual investors or the presence of a mutual fund. This implies a very tractable model with one objective function. ${ }^{3}$ Interestingly, the fractions of domestic and foreign wealth used when investing can be interpreted as the fractions of local respectively international investors present in the market. As a consequence, the fractions $\phi$ and $(1-\phi)$ are often interpreted as the fractions of domestic respectively foreign investors.

The basic assumptions of the model relate first of all to the process from making a loan by the investor to the actual investment by the borrower. Second, whether or not speculation is effective depends on the required number of players that are needed to exhaust the reserves of the central bank. Third, we need to give content to our concept of uncertainty about the fundamentals of the borrowing country. Finally, we will clarify what happens in our framework in case the borrower is unable to fully service debt repayments.

Concerning the first ingredient, we assume that there is a continuum of players normalized on $[0,1]$. At $t=0$ all players are investors, and the total amount lended in short-term loans to a bank in an emerging market is denoted by $\theta$. At each point in time an investor can either decide to roll-over his existing claims or to demand repayment and speculate against the currency. The bank in turn invests the proceipts of the loan into both shortterm and long-term projects. The foreign interest rate, $i^{*}$, is normalized to zero and the domestic interest rate is equal to a weighted average of the rate of return on short-term and long-term investments. The parameter $0 \leq \lambda \leq 1$ denotes the share of liquid investments. There is a cost associated with liquidating illiquid long-term investments expressed by the parameter $0 \leq k \leq 1$.

Concerning the required fraction of players that need to speculate in order for the fixed exchange rate regime to collapse we assume the following. $\rho_{t}$ denotes the fraction of investors that become speculators at time $t$. A country runs the risk of illiquidity either because of insufficient reserves to match foreign currency claims, or because of the banks' maturity mismatch between assets and liabilities, depending on the value of $k$. Foreign

\footnotetext{
${ }^{3}$ We did explore a, much more complicated, model with separate local and foreign investors. The qualitative results of the current model are the same.
} 
reserves of the borrowing country are equal to $R$. As soon as $\rho_{t}>\frac{R}{2 \theta}$ there are insufficient reserves to defend the fixed exchange rate regime. Also, if $\rho_{t}>\lambda$, the borrower has a problem as it is no longer able to service his debt without terminating long-term projects. The reason for having 2 in the denominator of $\frac{R}{2 \theta}$ follows from the fact that if an investor receives information about the economy that makes him decide not to roll-over his loan, it is also attractive for him to take a short-position against the currency. Through these two channels there is a double impact on the official reserves of withdrawing from the investment project. $\frac{R}{2 \theta}$ is the reserves to short-term debt ratio, where short-term debt refers to both domestic and foreign currency denominated loans.

For the third basic element of our framework we assume that the value of the fixed exchange rate, $\bar{e}$, is normalized to equal unity. We define the exchange rate as the number of foreign currency per home currency. The 'shadow floating' exchange rate, $e_{t}$, follows a random walk and will go either up or down with $u$ with probability $\frac{1}{2}$. $e_{t}$ refers to the exchange rate that would prevail at each moment in case the fixed exchange rate regime would collapse at that moment. Investors receive a signal at each point in time concerning $e_{t}$. A dynamic process for $u$ is given such that in each period, the probability than an investor receives a correct signal about $u$ is equal to $q \epsilon\left[\frac{1}{2}, 1\right]$, and the probability of receiving an incorrect signal is equal to $p=1-q$. We assume that these signals are conditionally independent given the true state of $u$, over time, and across investors. The parameter $q$ can be thought of as a measure of the quality of the signal. If $q$ is close to unity the information content of the signal is large. On the other hand, when $q$ is close to $\frac{1}{2}$ the signal does not reveal a great deal of information about the true state of the economy. At each point in time $u$ can thus be high, indicating strong fundamentals, or low indicating weak fundamentals. Also, given our assumption of a continuum of players, $q$ also denotes the fraction of players that received the correct signal. Similary, $p$ equals the fraction of players that received the wrong signal.

For the fourth ingredient of our model we assume that after the collapse of the fixed exchange rate regime all the investments are terminated, the players receive the scrap value of investments made, and the game ends. As a consequence, the loss associated with the scrap-value of the investment project in the respective currency, per unit invested, for the group of investors is equal to,

$$
l_{t}=\phi \lambda+(1-\phi) \lambda+\phi(1-\lambda) k+(1-\phi)(1-\lambda) k\left(e_{t}\right)-1
$$

Thus, as long as $e_{t}=\bar{e}=1$ and $k=1$, the loss is equal to zero. In case of a devaluation, the liquid assets are used in the defense of the fixed exchange rate regime and therefore accrue to those players who became speculators. That is, after a devaluation, the borrowing bank in the emerging market cancels all long-term investment projects and gives an equal share of the revenue collected to all players. As a consequence, the payoff to the players that were investing when a devaluation occurs is equal to:

$$
I\left(e_{t}\right)=\phi(1-\lambda) k+(1-\phi)(1-\lambda) k\left(e_{t}\right)-1
$$


Since short-term investments are cancelled first and converted using the official reserves, all liquid funds are used in the defense of the fixed exchange rate regime and are added to the payoff of the players that have speculated instead of continuing to invest. Thus, speculators receive an additional amount equal to $\phi \lambda+(1-\phi) \lambda=\lambda$ where it should be understood that this is shared among a fraction $\rho_{t}$ of the players. We denote:

$$
S\left(e_{t}\right)=I\left(e_{t}\right)+\frac{\lambda}{\rho_{t}}+\frac{\lambda}{\rho_{t}}\left[1-\left(e_{t}\right)\right]-c,
$$

as the payoff to speculators. Notice that apart from the speculative position (represented by the last two terms on the rhs of $(3)),\left(1-\rho_{t}\right) I\left(e_{t}\right)+\rho_{t} S\left(e_{t}\right)$ equals the expression in equation (1). The term $\frac{\lambda}{\rho_{t}}\left[1-\left(e_{t}\right)\right]$ refers to profits made on the maximum size of the short position. More specifically, this size refers to the amount of reserves available after simultaneous repayment of both the local and foreign currency denominated components of the loans that have been withdrawn. In other words, the size of the short-position completes the exhaustion of the official reserves. The fixed transaction cost $c$ is incurred because wealth denominated in the foreign currency is used in the speculation alongside local assets. ${ }^{4}$

\subsection{Solving the Model}

We concentrate on symmetric Nash equilibria in pure strategies. For simplicity only, we assume that $\lambda=\frac{R}{2 \theta}, q \geq \lambda$, and $p<\lambda$. Thus, if only a fraction $p$ of the investors engage in capital flight it is like a storm in a glass of water: the borrower has sufficient liquid funds to prevent either a collapse of the currency or cancellation of long-term investment projects. As a consequence, resident and international investors must both participate in order for the speculation to be effective in ending the fixed exchange rate regime. This assumption will be relaxed in section 3 .

Each player decides at time $t-1$ what his strategy will be at time $t$ depending on the possible signal received at that time and depending on how many players are expected to follow his action like lambs. The previous period exchange rate is common knowledge. In other words, all players know the complete history of signals and their decision whether to roll-over the loan or speculate instead depends on the expected exchange rate. We then have the following menu of options,

$$
f_{1}\left(e_{t}\right)=\left\{\begin{array}{lll}
\mathcal{I} & \text { if } & s=-u \\
\mathcal{I} & \text { if } & s=+u
\end{array}\right.
$$

\footnotetext{
${ }^{4}$ Moreover, we assume that the fixed cost of taking a short-position, $c$, applies only to foreign investors. Even though domestic investors face an opportunity cost when they decide to speculate, due to lost interest revenue, the difference in the borrowing versus lending interest rate gives rise to higher costs of speculative positions of foreign players. Additionally, extra costs may come from the existence of capital controls. Alternatively, $c$ could be interpreted as some form of capital control which affects foreign players only.
} 


$$
\begin{aligned}
& f_{2}\left(e_{t}\right)=\left\{\begin{array}{lll}
\mathcal{I} & \text { if } & s=-u \\
\mathcal{S} & \text { if } & s=+u
\end{array}\right. \\
& f_{3}\left(e_{t}\right)=\left\{\begin{array}{lll}
\mathcal{S} & \text { if } & s=-u \\
\mathcal{I} & \text { if } & s=+u
\end{array}\right. \\
& f_{4}\left(e_{t}\right)=\left\{\begin{array}{lll}
\mathcal{S} & \text { if } & s=-u \\
\mathcal{S} & \text { if } & s=+u
\end{array}\right.
\end{aligned}
$$

where $\mathcal{I}$ and $\mathcal{S}$ denote "invest" and "speculate" respectively. We can now solve for the moment of capital flight. Starting at $t=0$ from a situation where all players are investors, which requires a sufficiently high interest rate, we should solve for,

$$
\max e_{t-1}^{j, *} \quad \text { s.t. } \quad \pi_{t}^{j} \geq i
$$

where $\pi_{t}^{j}$ refers to the expected payoff from following strategy $j=2,3,4$. As long as fundamentals have not deteriorated to the extent as given by equation (8), we are in the business as usual case as in Caplin and Leahy (1994): investors all decide to roll-over existing loans and speculation is silent. As soon as $\pi_{t}^{j} \geq \pi^{1}=i$ an episode of capital flight occurs which, depending on the true signal at time $t$, could result in the collapse of the fixed exchange rate regime and partial default of the borrower. We are interested in the earliest moment when such an episode materializes and therefore we want to determine the maximum value of the equilibrium exchange rate such that imperfect information triggers speculative behavior. We have,

$$
\begin{gathered}
\pi_{t}^{2}=\frac{1}{2}\left[q i+p I\left(e_{t-1}+u\right)\right]+\frac{1}{2}\left[q S\left(e_{t-1}+u\right)-p c\right] \\
\pi_{t}^{3}=\frac{1}{2}\left[q S\left(e_{t-1}-u\right)-p c\right]+\frac{1}{2}\left[q i+p I\left(e_{t-1}+u\right)\right] \\
\pi_{t}^{4}=\frac{1}{2}\left[S\left(e_{t-1}-u\right)\right]+\frac{1}{2}\left[S\left(e_{t-1}+u\right)\right]
\end{gathered}
$$

We can solve the model for $e_{t-1}$ as this variable will be common knowledge as of time $t$. Using equations (2) and (3) we require, for $\pi_{t}^{2} \geq i$,

$$
e_{t-1}^{2, *} \leq \frac{1+(2-q) i+c-\phi(1-\lambda) k-2 \lambda}{[(1-\phi)(1-\lambda) k-\lambda]}-u
$$


For $\pi_{t}^{3} \geq i$ we require:

$$
e_{t-1}^{3, *} \leq \frac{1+(2-q) i+c-\phi(1-\lambda) k-2 \lambda}{[(1-\phi)(1-\lambda) k-\lambda]}+u,
$$

which for $u>0$ and given that we concentrate on the case where capital flight occurs at an overvalued peg of the exchange rate, implies that switching from being an investor to following strategy 3 becomes attractive at lower deterioration of fundamentals than switching to strategy 2 . We specify,

$$
A=(1-\phi)(1-\lambda) k-\lambda<0
$$

This assumption implies that we restrict the extent of exposure of the scrap-value of the investment project to exchange rate risk. Otherwise, capital flight could occur in the unlikely case where $e_{t-1}>1$ since in a sense then the appreciation of the currency after its collapse insures speculators against the illiquidity of the investment project due to the costs of abandonment of long-term projects. This scenario could become important if, for example, external conditions might warrant withdrawal from the investment project, but if $k$ is sufficiently small, this could be quite costly. However, in case the exchange rate would appreciate, full repayment would be possible and therefore undervaluation of the exchange rate could give rise to capital flight. However, we want to restrict attention to the more plausible case where capital flight as well as speculation occur at overvaluation of the exchange rate. Moreover we assume,

$$
B=1+(2-q) i+c-\phi(1-\lambda) k-2 \lambda>0
$$

which will prove to be convenient later. For $\pi_{t}^{4} \geq i$ we require:

$$
e_{t-1}^{4, *} \leq \frac{1+i+c-\phi(1-\lambda) k-2 \lambda}{A}
$$

Whether strategy 3 or strategy 4 solves $\max e_{t}$ s.t. $\pi_{t}^{3,4} \geq i$ first depends on whether, $e_{t-1}^{3, *} \geq e_{t-1}^{4, *}$ which requires:

$$
u \geq-\frac{(1-q) i}{A}
$$

Thus, for 3 to be the strategy that becomes attractive earlier than strategy 4 there must be sufficient volatility in the fundamentals. In that case strategy 3 is the symmetric Nashequilibrium in pure strategies. Thus, switching from investing always to investing sometimes becomes optimal at a lesser extent of deterioration of fundamentals than switching 
from investing always to speculating always if there is sufficient punishment to speculating while there is a chance that in fact fundamentals have improved considerably as indicated by a large, positive, value of $u$. The advantage of switching to strategy 3 instead of strategy 4 is that the former is still able to benefit from investing in case the exchange rate increased. So in case there is a lot of noise, it makes sense to speculate only if one received the information that fundamentals have deteriorated, and this is more so if the quality of information is better. If the fraction of foreign wealth, or the fraction of foreign players, becomes smaller, switching to 3 instead of to 4 is more attractive because the punishment of investing while one should have speculated is smaller. Then the exposure of ones portfolio to exchange rate risk in case of partial default is lower.

\subsection{Conclusions when Local and Resident Investors Need Each Other}

Above we saw that foreign and domestic wealth are withdrawn at the same moment in light of the condition that this is required for successful speculation; i.e. in light of our assumption that $q \geq \lambda$, but $p<\lambda$. If we assume that the noise surrounding the equilibrium exchange rate is indeed sufficiently large, so that switching from strategy 1 to strategy 3 becomes optimal, we can interpret the determinants of the moment of capital flight as follows.

Conclusion 1 A higher interest rate and larger costs associated with a short-position postpone the moment of capital flight.

Higher costs of speculation as well as a higher interest rate increase the numerator and given that the denominator is negative, $e_{t-1}^{3, *}$ has to be smaller as one can see in equation (13). Interpreting $c$ as coming from some form of capital control, this result implies that international investors, whose participation is required, are more willing to continue to roll-over existing claims despite weak fundamentals.

Conclusion 2 More accurate information about the fundamentals of the borrowing economy, fastens the timing of speculation.

A lower value of $q$ implies that the required deterioration of perceived fundamentals should be larger as well for an episode of capital flight to occur. More uncertain information makes it more attractive to remain an investor longer as the risk of speculating unsuccessfully on the basis of wrong information is larger.

Conclusion 3 Higher volatility in the equilibrium exchange rate facilitates an early start of capital flight.

For, as indicated by a larger value of $u$, the possibilities of large gains on a shortposition outweigh losses on the scrap-value of the investment project in case of partial default especially because switching to strategy 3 allows the player to take advantage of remaining an investor. 
Conclusion 4 A higher share of residential investments fastens the moment of capital flight.

For, according as there are more domestic players, the fraction of wealth that is exposed to exchange rate risk in case of default is smaller and there is more to gain from becoming a speculator. Also, a higher fraction of foreign investors postpones the moment of capital flight. From this perspective, resident investors are the main players in their market. This can easily be seen from,

$$
\frac{\partial e_{t-1}^{3, *}}{\partial \phi}=\frac{(1-\lambda) k[(2-q) i+c+1-\lambda-(1-\lambda) k]}{A^{2}} \geq 0
$$

Conclusion 5 When there are more liquid investments, capital flight occurs earlier.

For, we have,

$$
\frac{\partial e_{t-1}^{3, *}}{\partial \lambda}=\frac{-(2-\phi k) A+[1+k(1-\theta)] B}{A^{2}} \geq 0
$$

given the second condition as stated in equation (15). Notice the implication of this result. Under our assumption that $q \geq \lambda$, more reserves or liquid investments only speeds-up the moment of capital flight. That is, given that a sufficient number of players need to speculate against the fixed exchange rate regime it's better to use less reserves in trying to prevent the inevitable collapse of the fixed exchange rate regime. It does not matter in the defense, which is unsuccessful anyway, but the larger the reserves used in the defense, the more speculators are insulated from the exchange rate risk they face on their investments. Moreover, it allows them to make more profit on their short-positions.

Conclusion 6 The effect on the moment of capital flight when, in case of default, the capital loss on long-term investments is smaller, is uncertain.

This can be seen from,

$$
\frac{\partial e_{t-1}^{3, *}}{\partial k}=\frac{-(1-\lambda)[1+(1-\phi)(2-q) i+(1-\phi) c-2 \lambda]}{A^{2}}
$$

which could be either positive or negative. This result is due to the interaction between the following two opposing effects of a larger value of $k$. On the one hand, a large value of $k$ is attractive as it increases the scrap-value of the investment project in case of partial default. On the other hand, especially if $\phi$ is small, it increases the negative impact of a devaluation on the worth of the scrap-value. As one can see in equation (20), as $\phi$ becomes larger, the term in brackets in the numerator has a higher probability of becoming negative which will make the derivative positive. 
Whether or not capital flight at $e_{t-1}^{3, *}$ results in the collapse of the fixed exchange rate regime depends on whether the actual signal at time $t$ happens to equal $-u$ or $+u$. For, a fraction $q$ of the players receives the correct information, while a fraction $p$ receives the wrong information. Concerning strategy 3 , in case the actual signal turns out to be $+u$ only the fraction $p$ of the investors speculate and the fixed exchange rate regime will not collapse. On the other hand if the signal turned out to be $-u$, a fraction $q$ of the players will speculate and the fixed exchange rate regime will collapse.

\section{Local Versus Foreign Players}

Above it was shown that if there are more domestic investors relative to foreign ones, capital flight occurs at lower deterioration of fundamentals. Nevertheless, both the local and the foreign currency denominated share of the loan were withdrawn at the same moment. In this section we will solve the model above for a different assumption concerning the fraction of participants that need to speculate for the fixed exchange rate regime to collapse. More specifically, we assume that $q \phi=\lambda=\frac{R}{2 \theta}$ as well as $q(1-\phi)=\lambda=\frac{R}{2 \theta}$, which implies $\phi=\frac{1}{2}$, while $p<\lambda$. This scenario will tell us what factors determine whether it are local players that move first or their foreign counterparts as both are able to speculate against the fixed exchange rate regime successfully by themselves.

This decision of whether to recall the foreign currency denominated share or the local currency denominated share of the loan first depends, as usual, on a cost-benefit analysis. Irrespective of the share withdrawn and used as downpayment for speculation, if one received the correct information, the currency will collapse. However, refusing to rollover the foreign currency part of the loan first insures the investor against exchange rate risk, but requires at the same time a costly short position. Withdrawing domestic wealth first, exposes the foreign share to exchange rate risk after the partial default, but allows the player to take a costless short-position. Given that recalling each share will end the fixed value of the currency then, the decision of each player to speculate thus amounts to weighing the costs of a short-position against losses due to exposure to exchange rate risk.

Given that switching to strategy 3 dominates switching to strategy 2, and assuming sufficient volatility in $e_{t}$ we can focus on the case when it becomes attractive to switch from investing always to investing when fundamentals are strong and speculating when perceived fundamentals are weak. Checking whether foreign or domestic wealth is withdrawn first gives us the simplest way of analyzing whether it are the local or foreign players that speculate first, given that either party can force the collapse of the currency. The payoff from switching to strategy 3 by using local wealth amounts to:

$$
\begin{aligned}
\pi_{t}^{3, l}= & \frac{1}{2} q\left[-1+(1-\lambda) k\left(e_{t-1}-u\right)+\frac{\lambda}{q \phi}\left[2-\left(e_{t-1}-u\right)\right]\right] \\
& +\frac{1}{2}\left[q i+p I\left(e_{t-1}-u\right)\right]
\end{aligned}
$$


where the superscript $l$ refers to speculating with domestic wealth. The second half of equation (21) is the same as in equation (10) as the player invested on the basis of the wrong signal and still has both domestic and foreign currency claims on the borrower. Also we have for withdrawing foreign claims:

$$
\begin{aligned}
\pi_{t}^{3, f}= & \frac{1}{2}\left[q\left[-1+(1-\lambda) k+\frac{\lambda}{q(1-\phi)}\left[2-\left(e_{t-1}-u\right)\right]-c\right]-p c\right] \\
& +\frac{1}{2}\left[q i+p I\left(e_{t-1}-u\right)\right]
\end{aligned}
$$

where the superscript $f$ refers to the refusal to roll-over investments made in the foreign currency. Obviously, the comparison reduces to the case where players indeed speculate, i.e. the first half of equations (21) and (22), and amounts to weighing the costs attached to speculating with foreign wealth to its insurance character against exchange rate risk in case of default. As $\phi=\frac{1}{2}$ we don't have to be concerned that location matters because of different degrees of competition for the official reserves of the central bank of the borrowing country. Clearly, for $\pi_{t}^{3, l} \geq \pi_{t}^{3, f}$ we have $e_{t-1}^{3, *, l} \geq e_{t-1}^{3, *, f}$. This is the case if,

$$
e_{t-1} \geq 1+u-\frac{c}{q(1-\lambda) k}
$$

Thus, local players move out first if the exchange rate is not overvalued too much. When the costs of speculation are larger the degree of overvaluation of the exchange rate, such that transferring local wealth first is still most attractive, can be larger too. The same holds for a lower value of $u$ as well as a lower value of $q(1-\lambda) k$, for then the extent of exposure to exchange rate risk in the case of default is smaller. This makes it relatively more attractive to withdraw assets denominated in the domestic currency first. Thus,

Conclusion 7 Higher costs of speculation, smaller fluctuations in fundamentals, lower information quality, and more liquid long-term investments make it more likely that domestic investors take the lead in starting speculation against the fixed exchange rate regime.

\section{The Role of Information Quality}

Theoretical papers studying the flow of information and transparency have utilized different forms of heterogeneity. The interaction between informed and uninformed investors can easily give rise to herding behavior and contagion effects of a financial crises in one country onto another (see, for example, Calvo and Mendoza, 1999). ${ }^{5}$ Although information is a key

\footnotetext{
${ }^{5}$ See Devenow and Welch (1996), for an overview of herding in financial economics. Benabou and Laroque (1992) focus on manipulation in assets markets by participants that have access to priviliged information. Hirshleifer, Subrahmanyam, and Titman (1994) use a model to analyze trading behavior and equilibrium information acquisition when some investors receive common private information before others.
} 
element in the theoretical models of recent crises, they do not distinguish between local and foreign investors explicitly. An exception is Greenwald (1998) who builds a model with an a-symmetry of information between well-informed local firm and bank managements and less well-informed outside investors. The information based restrictions on financial markets are then shown to amplify rather than attenuate local disturbances.

In fact the way we model the a-symmetry of information, implies not only that local players receive better information, but also that resident investors have better knowledge about each other's information than foreign players do. In essence therefore, this third reason why location matters implies that domestic parties absorb their information from a better and similar source, while international investors obtain lower quality, more diversified, information. We show that such an information a-symmetry makes it more likely that indeed the local players engage in capital flight and speculation first; i.e. the fraction of the loan denominated in the home currency is recalled and used for speculative purposes at a lower degree of overvaluation of the currency than the share of the loan denominated in the foreign currency.

To formalize the difference in information quality between local and foreign players in the easiest way possible, we assume that local wealth 'carries' a higher information content than foreign wealth about the domestic economy. We assume that $q^{l} \phi+q^{f}(1-\phi)=$ $q \phi+q(1-\phi)=q$ with $q^{l} \geq q$ referring to the information attached to local wealth.

Interestingly, the moment of capital flight for the case where both local and foreign wealth will be needed for successful speculation is the same as without the information a-symmetry as the average quality of information is the same as it used to be in section 2. When we interpret local and foreign wealth as domestic respectively international investors, this result crucially depends on assuming that players know each other's quality of information. Also, given that $q^{l} \geq q^{f}$ we can interpret this situation as resembling a situation in which local players have better knowledge about each other's information sets than foreign players do. For, if a local player receives the signal $s$ he expects that $q^{l}\left(q^{l}+q^{f}\right)+p^{l}\left(p^{l}+p^{f}\right)$ have received the same signal while international investors expect that a lower fraction, equal to $q^{f}\left(q^{f}+q^{l}\right)+p^{f}\left(p^{f}+p^{l}\right)$, of the market participants has received the same signal.

Conclusion 8 Given the condition that the participation of both domestic and foreign investors is needed for successful speculation, varying the quality of information among both parties while maintaining the average quality of information in the market, does not affect the timing of capital flight.

We now turn attention to the situation where $q^{l} \phi=\lambda=\frac{R}{2 \theta}$ as well as $q^{f}(1-\phi)=$ $\lambda=\frac{R}{2 \theta}$, while $p^{l} \phi<\lambda$ as well as $p^{f}(1-\phi)<\lambda$. This presents the case where either party has sufficient resources to exhaust the official reserves of the central bank in the emerging market where the borrowing bank is located. We have, given that $\phi=\frac{1}{2}$, 


$$
\begin{aligned}
\pi_{t}^{3, l}= & \frac{1}{2} q^{l}\left[-1+(1-\lambda) k\left(e_{t-1}-u\right)+\frac{\lambda}{2 q^{l}}\left[2-\left(e_{t-1}-u\right)\right]\right] \\
& +\frac{1}{2}\left[q^{l} i+p^{l} I\left(e_{t-1}-u\right)\right]
\end{aligned}
$$

and:

$$
\begin{aligned}
\pi_{t}^{3, f}= & \frac{1}{2}\left[q^{f}\left[-1+(1-\lambda) k+\frac{\lambda}{2 q^{f}}\left[2-\left(e_{t-1}-u\right)\right]-c\right]-p^{f} c\right] \\
& +\frac{1}{2}\left[q^{f} i+p^{f} I\left(e_{t-1}-u\right)\right]
\end{aligned}
$$

so that for $\pi_{t}^{3, l} \geq \pi_{t}^{3, f}$ we now require,

$$
e_{t-1} \geq 1+u-\frac{c}{q(1-\lambda) k}-\frac{\left(q^{l}-q^{f}\right) i}{q(1-\lambda) k}
$$

Then, compared to the requirement as given in equation (23) we have:

Conclusion 9 In case the illiquidity facing the borrower is such that either local or foreign investors can attack the fixed exchange rate successfully, the likelihood that domestic players are the ones that move first is increasing in the a-symmetry of information quality between the two parties.

\section{Adding a Post-Crisis Tax on Resident Investors}

Apart from informational differences, domestic and foreign investors can be distinguished because, even with the same signals, a domestic investor in Indonesia may not respond in the same way as an investor in New York (see Stiglitz, 1998). Many theories have focused on tax and tax-like distortions that reduce returns and add risk to domestic financial and physical assets. An a-symmetric probability of taxation could give rise to two-way capital flows as is shown by Khan and Hague (1985); i.e. private capital flight occurring simultaneously with private foreign borrowing.

It is plausible to assume that local and international investors are treated, or affected, differently by tax authorities in case the (country of the) borrower in our model is in financial difficulty. More specifically, we assume that a tax is levied in the event of a crisis on the share of the loan denominated in the home currency in case it has not been recalled on time, but not on the share of the loan that is denominated in the foreign currency. For example, such a tax could be indirect such as an inflation tax or exchange rate depreciation. Alternatively, it could reflect a direct capital tax which could be levied to 
balance the budget in the event of a financial crisis. The incentives for capital flight related to taxation issues could also come from, as in Eaton (1987), the expectation of increased tax obligations created by the potential nationalization of private debt in the face of a financial crisis. If the government borrows abroad directly to finance public goods, the anticipation of increased tax obligation could also result in capital flight (see Eaton and Gersovitz, 1989).

Consequently, different tax treatment between resident and international investors can be expected and we will analyze how this affects the moment of capital flight when both domestic and foreign money needs to be withdrawn for successful speculation first. Next we will discuss how it affects the choice between withdrawing either foreign or domestic wealth and will argue that such a policy response in the event of a crisis makes it more likely that local players take the lead in starting a process of capital flight. When both parties' participation is required for successful speculation we have, denoting the tax by $\tau$,

$$
\begin{aligned}
\pi_{t}^{3}= & \frac{1}{2}\left[q\left[-1+S\left(e_{t-1}-u\right)-\phi \tau(1-\lambda) k\right]-p c\right] \\
& +\frac{1}{2}\left[q i+p\left[I\left(e_{t-1}-u\right)-\phi \tau(1-\lambda) k\right]\right]
\end{aligned}
$$

We are interested in finding $e_{t-1}^{3, *}$ such that $\pi_{t}^{3} \geq i$, the solution of which is:

$$
e_{t-1}^{3, *} \leq \frac{1+(2-q) i+c-\phi(1-\lambda) k(1-\tau)-2 \lambda}{A}+u
$$

One can easily establish that for the same value of $u$ as given in equation (17) we have $e_{t-1}^{3, *} \geq e_{t-1}^{4, *}$. Assuming sufficient volatility in the equilibrium exchange rate we can therefore restrict attention to the case where players switch from always investing to strategy 3 . We have:

$$
\frac{\partial e_{t-1}^{3, *}}{\partial \tau}=\frac{\phi(1-\lambda) k}{A} \leq 0
$$

In a sense then, taxation of domestic wealth in the event of a financial crisis in the country of the borrower postpones the occurrence of such a crisis since the effect of the tax is similar to a lower scrap-value of investments made in the event of partial default.

Conclusion 10 Given the condition that the participation of both domestic and investors is needed for successful speculation, expectations of higher post-crisis taxes levied on domestic wealth postpones the moment of capital flight.

The more interesting effect of an a-symmetry in tax treatment, however, operates via its effect on the incentives of moving domestic respectively foreign currency denominated 
wealth first. To study this scenario we postulate the, by now familiar, requirement that $q \phi=\lambda=\frac{R}{2 \theta}$ as well as $q(1-\phi)=\lambda=\frac{R}{2 \theta}$, while $p<\lambda$. We then have,

$$
\begin{aligned}
\pi_{t}^{3, l}= & \frac{1}{2} q\left[-1+(1-\lambda) k\left(e_{t-1}-u\right)+\frac{\lambda}{q \phi}\left[2-\left(e_{t-1}-u\right)\right]\right] \\
& +\frac{1}{2}\left[q i+p\left[I\left(e_{t-1}-u\right)-\phi \tau(1-\lambda) k\right]\right]
\end{aligned}
$$

and:

$$
\begin{aligned}
\pi_{t}^{3, f}= & \frac{1}{2}\left[q\left[-1+(1-\lambda)(1-\tau) k+\frac{\lambda}{q(1-\phi)}\left[2-\left(e_{t-1}-u\right)\right]-c\right]-p c\right] \\
& +\frac{1}{2}\left[q i+p\left[I\left(e_{t-1}-u\right)-\phi \tau(1-\lambda) k\right]\right]
\end{aligned}
$$

so that for $\pi_{t}^{3, l} \geq \pi_{t}^{3, f}$ we require,

$$
e_{t-1} \geq(1-\tau)+u-\frac{c}{q(1-\lambda) k}
$$

The tax rate increases the extent to which the exchange rate can be overvalued while it is still attractive to move locally denominated funds out first.

Conclusion 11 In case the illiquidity facing the borrower is such that either local or foreign investors can attack the fixed parity successfully, the expectation of higher post-crisis taxation makes it more likely that domestic investors take the lead in refusing to roll-over loans.

\section{Government Guarantees}

Although we focused so far on reasons that made it more likely that residents take the lead in case either party can force the collapse of the currency, there are also differences because of location that in fact make it more likely that international investors are the ones that play a dominant role. For example, in our model it is obvious that this is the case if domestic lenders to the banking sector in the emerging market are protected by government guarantees. In case these guarantees work discriminatory in favor of residents, it becomes attractive to withdraw the foreign part of the loan first. For, then the domestic part is insured against the partial default of the borrower due to the illiquid nature of its long-term investments. We can analyze this situation in our model by assuming that local parties receive full repayment of their loan in case there is partial default. Then the payoff from switching to strategy 3 by using local wealth is equal to: 


$$
\begin{aligned}
\pi_{t}^{3, l}= & \frac{1}{2} q\left[-1+(1-\lambda) k\left(e_{t-1}-u\right)+\frac{\lambda}{q \phi}\left[2-\left(e_{t-1}-u\right)\right]\right] \\
& +\frac{1}{2}\left[q i+p\left(-1+\phi(1-\lambda)+(1-\phi)(1-\lambda) k\left(e_{t-1}-u\right)\right)\right]
\end{aligned}
$$

Thus, the case of complete insurance amounts to setting $k=1$ on the fraction of the loan made in the domestic currency in equation (21). The profitability expression for withdrawing wealth denominated in the foreign currency first, we obtain the following slightly modified version of equation (24):

$$
\begin{aligned}
\pi_{t}^{3, f}= & \frac{1}{2}\left[q\left[-1+(1-\lambda)+\frac{\lambda}{q[1-\phi]}\left[2-\left(e_{t-1}-u\right)\right]-c\right]-p c\right] \\
& +\frac{1}{2}\left[q i+p\left(-1+\phi(1-\lambda)+(1-\phi)(1-\lambda) k\left(e_{t-1}-u\right)\right)\right]
\end{aligned}
$$

As a consequence, the question which party moves out first amounts to the case presented in equation (23) with $k=1$ and we reach the following conclusion:

Conclusion 12 The presence of government guarantees that discriminatory insure loans made by residents makes it more likely that international investors take the lead in starting an episode of capital flight.

In essence this is a standard moral hazard argument as local players continue to invest, even though lending to the bank may become more risky because of overvaluation, realizing that either they receive the high interest rate in the good state of nature or will be compensated in the bad state.

\section{Summary and Policy Implications}

In this paper we used a very simple model to study the consequences of different causes for locational heterogeneity of investors for the timing and determinants of an episode of capital flight. Although our model focused on return differential incentives as the cause for capital flight, other reasons for capital flight are related to either portfolio diversification incentives or relative risk incentives (see Collier et al., 1999). About the latter, for example Stiglitz (1998) argues that the high correlation between returns on human and physical capital within a country means that domestic investors are less diversified and therefore should act in a more risk-averse manner.

In our framework as long as fundamentals, as formalized by the extent to which a currency is overvalued, have not deteriorated sufficiently, investments are in the business as usual phase. This silence of speculation is disturbed as soon as perceived fundamentals have deteriorated enough to activate a sufficient flock of lambs that engage in capital flight. 
We saw that the moment when at least some investors are no longer willing to roll-over their loans is determined by such factors as the interest rate differential on liquid and illiquid investments, the costs associated with speculation, the quality of information, the volatility in the equilibrium exchange rate, the relative importance of investments made in the domestic and foreign currency, the degree of illiquidity facing the borrower, as well as the termination costs associated with illiquid investments. Also we argued that the fraction of investments denominated in the local, respectively foreign, currency could and should be interpreted as the fraction of resident, respectively international, investors.

The respective roles played by domestic and foreign players depends crucially on whether both parties need each other or not for successful speculation against the fixed exchange rate parity. Depending on this requirement about the fraction of market participants needed, domestic investors could be hard to disentangle from foreign players from an empirical point of view. This is because foreign players adjust their threshold for accepting overvaluation of the exchange rate to that of domestic parties and vice versa when both are needed. If the participation of both is required we saw that a-symmetric tax treatment postpones the moment of the attack. Also, local players having access to better information than foreign ones while keeping the average quality of information in the market unaltered was seen not to affect the moment of speculation.

On the other hand, when both parties do not need each other for successful speculation, the question of whether it are the local or the international investors that move out first depends on the relative importance of the (higher) costs associated with taking a shortposition versus the exposure to exchange rate risk associated with investments made in the foreign currency. These costs attached to speculation are lower for local players on the one hand, while on the other hand, exchange rate risk affects that fraction of the loan that is denominated in the foreign currency. In case the former outweighs the latter, the local players are more eager to move out first.

Different tax treatment of both players was seen to increase the likelihood that indeed the local players refuse to roll-over short-term loans first. Also, we argued that if resident investors indeed have access to better quality of information as well as better knowledge about their respective information sets, then the chance that domestic investors take the lead with shipping their wealth abroad increases. Discriminatory government guarantees were shown to increase the probability that it are the international investors that play a dominant role.

As far as the costs of speculation are coming from capital controls affecting capital inflows denominated in the foreign currency, we can say the following. As long as both domestic and foreign players are needed for successful speculation, higher costs will postpone capital flight. However, in case each party can trigger a financial crisis without the assistance of the other, it will be more likely that capital flight will start at home. As a consequence, our model confirms the current intuition that restrictions only targeted at capital flows coming from abroad could leave much to be desired.

Additionally, our model showed that improving transparency, in case it does not simultaneously improve fundamentals, only postpones capital flight if fundamentals are sound. For, a higher value of the quality of information in our model only lowers the threshold for 
accepting weak fundamentals. Convergence of the quality of information between local and foreign players when both do not need each other, again, will only postpone a financial crisis if the convergence takes place in the direction of the least informed trader in the presence of weak fundamentals.

About using the interest rate as an instrument to limit capital flight, we derived that higher interest rates postpone the timing of speculative behavior. However, such a higher interest rate can, in our model, only come from investing more in illiquid investment projects which in turn would fasten the moment of capital flight. In other words, the higher interest rate reflects higher risk associated with investing. As a consequence, the usage of the interest rate as an instrument to prevent capital flight can be characterized as a mixed blessing. Similarly, a better asset-liability match of the bank in the emerging market that intermediates the loans to the private sector, would reduce interest rates leaving its impact on the moment of capital flight uncertain.

In a sense the best policy advice following from our model is to prevent misalignment of the exchange rate. If this is not possible however, other suggestions are as follows. In case defending the fixed exchange rate regime by using international reserves is expected to be fruitless, then don't defend at all. The usage of such reserves only increases the scrap-value of investments made as well as total profits from short-positions. Having more reserves would only help in preventing a crisis in case it completely insulates the country from any successful speculative attack. Notice that an external short-term debt to reserves ratio smaller than one is not a sufficient requirement for this too occur, since one should take account of refusal to roll-over loans as well as pure speculation, by both foreign and domestic parties. Portfolio diversification on the other hand, by making domestic parties less prominent in the home financial market, could work. This increases the probability that both parties will need each other for successful speculation. For countries where local players used to have a lower threshold for accepting weak fundamentals than international investors, for example because of the way the tax system is structured, this could postpone a financial crisis.

\section{References}

1. Benabou, R. and G. Laroque, 1992. Using Privileged Information to Manipulate Markets: insiders, gurus, and credibility, Quarterly Journal of Economics 107, 921958.

2. Botman, D.P.J. and H. Jager, 2002. Coordination of Speculation, Journal of International Economics (forthcoming).

3. Calvo, G. and E. Mendoza, 1999. Rational Herd Behavior and the Globalization of Securities Markets, Journal of International Economics 51, 79-113.

4. Caplin, A. and J. Leahy, 1994. Business as usual, market crashes, and wisdom after the fact, American Economic Review 84, 548-565. 
5. Chari, V.V. and R. Jagannathan, 1988. Banking Panics, Information, and Rational Expectations Equilibrium, Journal of Finance 43, 749-761.

6. Choe, H., B.C. Kho, and R.M. Stulz, 1999. Do Foreign Investors Destabilize Stock Markets? The Korean experience in 1997, Journal of Financial Economics 54, 227 264.

7. Choe, H., B.C. Kho, and R.M. Stulz, 2000. Do Domestic Investors have more Valuable Information about Individual Stocks than Foreign Investors, NBER Working Paper 8073 .

8. Collier, P., A. Hoeffler, and C. Pattillo, 1999. Flight Capital as a Portfolio Choice, Policy Research Working Paper 2066, World Bank, Washington D.C.

9. Devenow, A. and I. Welch, 1996. Rational Herding in Financial Economics, European Economic Review 40, 603-615.

10. Diamond, D. and P. Dybvig, 1983. Bank Runs, Deposit Insurance, and Liquidity, Journal of Political Economy 91, 401-419.

11. Eaton, J. 1987. Public Debt Guarantees and Private Capital Flight, World Bank Economic Review 1, 377-395.

12. Eaton, J. and M. Gersovitz, 1989. Country Risk and the Organization of the International Capital Transfer, in G. Calvo, R. Findlay, P. Kouri, and J. Macedo, eds., Debt, Stabilization, and Development, Oxford, England, Blackwell.

13. Frankel, J. and S. Schmukler, 1996. Country Fund Discounts and the Mexican Crisis of December 1994: did local residents turn pessimistic before international investors?, Open Economies Review 7, 511-534.

14. Frankel, J. and S. Schmukler, 1998. Country Funds and Asymmetric Information, World Bank Working Paper 1493.

15. Greenwald, B., 1998. International Adjustments in the Face of Imperfect Financial Markets, Paper prepared for the Annual World Bank Conference on Development Economics, Washington D.C.

16. Hirshleifer, D., A. Subrahmanyam, and S. Titman, 1994. Security Analysis and Trading Patterns When Some Investors Receive Information before Others, Journal of Finance 49, 1665-1698.

17. International Monetary Fund, 1995. International Capital Markets: developments, prospects, and policy issues, Washington D.C.

18. Kaufmann, D., G. Mehrez, and S. Schmukler, 1999. Predicting Currency Fluctuations and Crises: do resident firms have an informational advantage?, World Bank Working Paper 2259, Washington D.C. 
19. Khan, M. and N.U. Haque, 1985. Foreign Borrowing and Capital Flight: a formal analysis, IMF Staff Papers 32, 606-628.

20. Kim, W. and S. Wei, 1999. Foreign Portfolio Investors Before and During a Crisis, NBER Working Paper 6968.

21. Stiglitz, J.E., 1998. Knowledge for Development: economic science, economic policy, and economic advice, Paper prepared for the Annual World Bank Conference on Development Economics, Washington D.C. 